\title{
Directional Migration Behavior of Alloying Elements in the Rafting Process of the Single Crystal Superalloy DD6
}

\author{
Zhang Shiming ${ }^{1}, \quad$ Yu Jingui ${ }^{1}$, Huang Zeyin ${ }^{1}$, Huang Rong ${ }^{1}$, Liu Shengfa ${ }^{1}$, \\ Zhang Qiaoxin', Yue Zhufeng ${ }^{2}, \quad$ Li Xuewu ${ }^{1}$ \\ ${ }^{1}$ Wuhan University of Technology, Wuhan 430070, China; ${ }^{2}$ Northwestern Polytechnical University, Xi'an 710072, China
}

\begin{abstract}
This paper investigated the directional migration behavior of the alloying elements in the rafting process of the single crystal superalloy DD6 with [001] orientation under $300 \mathrm{MPa}$ at $1000{ }^{\circ} \mathrm{C}$. The microstructure of the single crystal superalloy DD6 was acquired by SEM. The results indicate that the rafting direction of $\gamma^{\prime}$ phase is nearly perpendicular to stress axis. The matrix channel running parallel to the stress axis gets wider, but it will fade away gradually in vertical direction. Statistical analysis of the alloy components by TEM reveals the directional migrations of the elements Al, Re and $\mathrm{W}$ in the single crystal superalloy DD6. The element $\mathrm{Al}$ spreads to the matrix channel which is parallel to the stress axis, while Re and $\mathrm{W}$ diffuse to the matrix channel which is perpendicular to the stress axis, and obviously concentrate in the crossing area of the above mentioned channels.
\end{abstract}

Key words: Ni-based superalloys; creep; directional migration; diffusion

Single crystal superalloys have been widely used for turbine blades due to their superior thermal resistance and melt resistance capabilities ${ }^{[1-4]}$. The typical microstructure of these alloys involves the $\gamma^{\prime}\left(\mathrm{Ni}_{3} \mathrm{Al}\right.$ cuboidal precipitates) phase with $\mathrm{L1}_{2}$ structure coherently embedded in a solid solution matrix of $\gamma$ (Ni matrix) phase ${ }^{[5-7]}$. The high temperature creep properties of recently developed nickel-base single crystal superalloys are mainly improved by introducing a large amount of the refractory elements such as $\mathrm{Cr}, \mathrm{Co}, \mathrm{Mo}, \mathrm{Re}, \mathrm{Ru}$, $\mathrm{Ta}, \mathrm{Ti}$ and $\mathrm{W}^{[8-10]}$. Recently, $\mathrm{Yu}$ et al. ${ }^{[9]}$ have studied the distribution behaviors of Re in the Ni-Al-Re and Ni-Al-Re-Ru single-crystal alloys. The element Re obviously segregated to the dendritic core in the Ni-Al-Re alloy. The segregation of Re became stronger with the addition of $\mathrm{Ru}$ in the Ni-Al-Re-Ru alloy. Cheng et al. ${ }^{[10]}$ reported that the $\mu$ phase was mainly composed of $\mathrm{Ni}, \mathrm{Cr}, \mathrm{Co}, \mathrm{W}$ and $\mathrm{Re}$. Contents of the $\mathrm{Ni}, \mathrm{W}$ and Re have a large variation in the $\mu$ phase. High content of $\mathrm{Ni}$ but low content of $\mathrm{W}$ and $\mathrm{Re}$ at the early stage of thermal exposure are due to different atomic diffusion rates of these elements in the matrix. In Latief et al.'s work ${ }^{[11]}$, it also showed that the Re content improved the creep strength of substrate despite it provoked the TCP phase formation in the diffusion zone. Besides, Tan et al. ${ }^{[12]}$ showed that the addition of $3 \mathrm{wt} \% \mathrm{Ru}$ improved the creep rupture life of a single crystal Ni-based superalloy. The change of $\gamma / \gamma^{\prime}$ lattice misfit in the initial microstructure is believed to be the key role of $\mathrm{Ru}$ in the high-temperature creep deformation. These articles gave a more comprehensive description of the influence of elements on creep rupture. Although they studied the effects of $\mathrm{Re}, \mathrm{Ru}$ and $\mathrm{W}$ elements and element diffusion behavior, they did not have an in-depth discussion about the influence of other alloy elements on the creep rupture.

The present study is aimed at elucidating the directional migration behavior of the element in the rafting process of the single crystal superalloy DD6 with [001] orientation under $300 \mathrm{MPa}$ at $1000{ }^{\circ} \mathrm{C}$, which may help us further understand the creep mechanism accurately and completely.

\section{Experiment}

The single crystal superalloy DD6 used in the present

Received date: June 19, 2015

Foundation item: National Natural Science Foundation of China (51210008)

Corresponding author: Zhang Qiaoxin, Ph. D., Professor, School of Mechanical and Electronic Engineering, Wuhan University of Technology, Wuhan 430070, P. R. China, Tel: 0086-27-87218976, E-mail: zhangqx@whut.edu.cn 
experiment was the second generation single crystal superalloy which is developed by Chinese research institution and has been used commercially in the turbine blades ${ }^{[2]}$. Its specific nominal composition is shown in Table 1. The [001] orientation of single crystal superalloy DD6 bar prepared by a selecting method in a high temperature gradient directional solidification apparatus. The maximum deviation of the rod axis from [001] direction was laid within $7^{\circ}$. The single crystal superalloy DD6 was fully heat treated, i.e. solution heat treated $\left(1290{ }^{\circ} \mathrm{C} / 1 \mathrm{~h}+1300{ }^{\circ} \mathrm{C} / 2 \mathrm{~h}+1315{ }^{\circ} \mathrm{C} / 4 \mathrm{~h} / \mathrm{AC}\right)$, and aging heat treated for two stages $\left(1120{ }^{\circ} \mathrm{C} / 4 \mathrm{~h} / \mathrm{AC}+\right.$ $\left.870{ }^{\circ} \mathrm{C} / 32 \mathrm{~h} / \mathrm{AC}\right)^{[13-15]}$. Then the single crystal superalloy DD6 bar was processed into the standard tensile creep specimen, and their dimensions were $\Phi 5 \mathrm{~mm} \times 25 \mathrm{~mm}$. Creep tests were carried out on the above specimens until creep rupture under $300 \mathrm{MPa}$ at $1000{ }^{\circ} \mathrm{C}$ by a high temperature creep testing machine GTW504 ${ }^{[16]}$. The microstructure morphology was observed before and after creep by SEM (FEI Quanta $300)^{[17,18]}$. The statistical analysis of the size and the content of $\gamma$ and $\gamma^{\prime}$ phases was conducted by the ImagePro image (Media Cybernetics, Silver Spring, MD) ${ }^{[19]}$. The contents of the elements $\mathrm{Al}, \mathrm{Re}, \mathrm{Co}$ and $\mathrm{Mo}$ in the single crystal superalloy DD6 before and after creep were obtained by TEM $\left(\right.$ JEM-2100) ${ }^{[20]}$.

\section{Results and Discussion}

\subsection{Microstructure evolution during creep}

The single crystal superalloy DD6 consists of the cubic $\gamma^{\prime}$ phase embedded coherently in the $\gamma$ matrix phase after full heat treatment, as shown in Fig.1. The size of the cubic $\gamma^{\prime}$ phase is about $500 \mathrm{~nm}$, and the width of $\gamma$ matrix phase is approximately $70 \mathrm{~nm}$. It is widely believed that there are two mutually perpendicular matrix channels in the single crystal

Table 1 Nominal composition of the alloy (wt\%)

\begin{tabular}{cccccccccc}
\hline Cr & Co & Mo & W & Ta & Re & Hf & Al & Ti & Ni \\
\hline 4.3 & 9.0 & 2.9 & 8.0 & 7.2 & 2.0 & 0.1 & 5.7 & - & Bal. \\
\hline
\end{tabular}

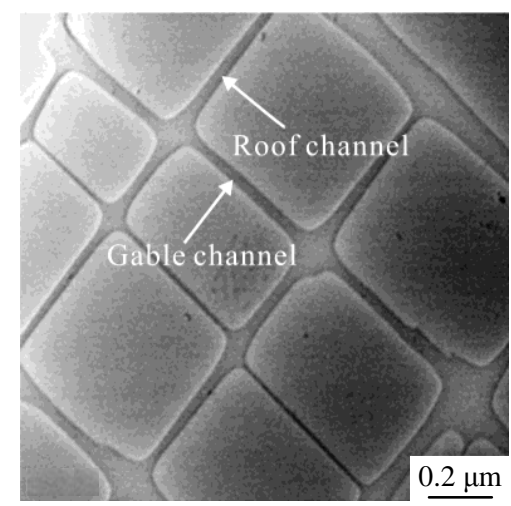

Fig.1 Microstructure of the single crystal superalloy DD6 after full heat treatment superalloy, roof channel and gable channel.

The widths of $\gamma$ matrix phases are not of significant differences between the roof channel and the gable channel before the creep of the single crystal superalloy DD6. The micro- structures of creep rupture in different regions are shown in Fig.2. The specimen is slowly loaded in tension along the [001] direction until it breaks. The proximal and distal microscopic structures of the fracture are observed. Compared to the cubic $\gamma^{\prime}$ phase in Fig.1, the morphology of $\gamma^{\prime}$ phase changes significantly in Fig.2a and Fig.2b. The $\gamma^{\prime}$ phase has completely rafted into a long strip, and its width is $700 \mathrm{~nm}$ in the vertical rafting direction in Fig.2a. Meanwhile, the gable channel has completely disappeared, and the width of roof channel is $200 \mathrm{~nm}$. It shows that $\gamma^{\prime}$ phase expands along the direction which is perpendicular to the stress axes, and finally forms P-type microstructure. In the rafting process, the size of $\gamma^{\prime}$ phase becomes larger, the gable channel disappears, and the size of the roof channel becomes smaller. Some of the $\gamma^{\prime}$ phases raft into long strips, while others are in a roughly circular area or an elliptical area which are typically $600 \mathrm{~mm}$ in width in Fig.2b. The $\gamma / \gamma^{\prime}$ interface changes from orderliness into chaos. There is only a small number of gable channels which are parallel to the stress axis. Others are mainly the roof channel, and the width is about $300 \mathrm{~nm}$.

After a solid solution and aging treatment, precipitated phase $\gamma^{\prime}$ is arranged periodically along < $001>$ direction and maintains a coherent relationship with matrix $\gamma$ phase. The $\gamma / \gamma^{\prime}$ coherent interface has the same degree of mismatch and elastic strain energy. Under the condition of high temperature

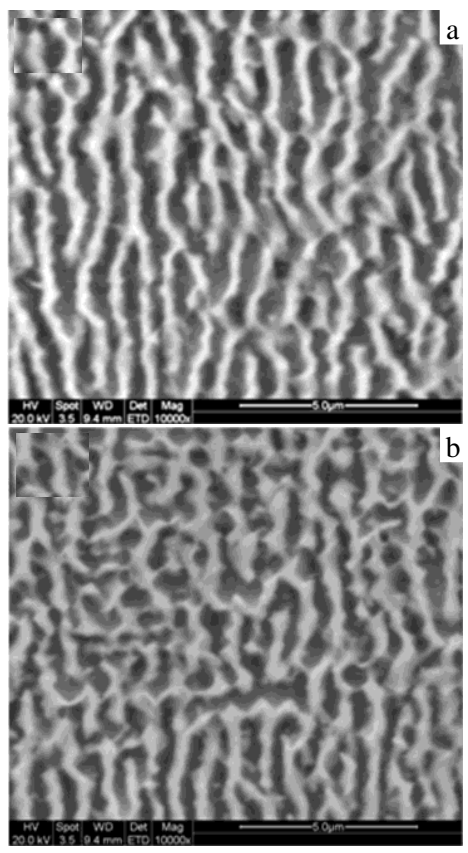

Fig.2 Microstructures of the single crystal superalloy DD6 after creep rupture: (a) a proximal fracture and (b) a distal fracture 
and applied stress, the change of elastic strain energy is inconsistent in different $\gamma / \gamma^{\prime}$ interfaces. When one or two groups of coherent strain energy in $\gamma / \gamma^{\prime}$ interface decrease, the other groups increase. The increase of coherent strain energy of the whole system becomes the driving force of $\gamma^{\prime}$ phase directional coarsening. When the matrix phase $\gamma$ creep deformation occurs, the precipitated phase $\gamma^{\prime}$ is still in a state of elastic deformation ${ }^{[21,22]}$. According to this point view, the change of the lattice constant of the $\gamma^{\prime}$ phase can be ignored when $\gamma$ phase presents elastic deformation. We hypothesize that the lattice constant in the coherent interface has the following equation:

$$
\alpha_{\gamma^{\prime}}^{100}=\alpha_{\gamma^{\prime}}^{010}=\alpha_{\gamma^{\prime}}^{001}
$$

The mismatch degree of DD6 alloy is negative, i.e. $\alpha_{\gamma^{\prime}}<\alpha_{\gamma}$. The tensile load is applied in the [001] direction. As the value of the $\alpha_{\gamma}^{001}$ increases, the values of $\alpha_{\gamma}^{100}$ and $\alpha_{\gamma}^{010}$ will decrease. Under the condition of $\alpha_{\gamma^{\prime}}^{100}=\alpha_{\gamma^{\prime}}^{010}=\alpha_{\gamma^{\prime}}^{001}$, according to the formula of the $\delta=2\left(\alpha_{\gamma^{\prime}}-\alpha_{\gamma}\right) /\left(\alpha_{\gamma^{\prime}}+\alpha_{\gamma}\right)^{[23]}$, it can be deduced that $\Delta \delta^{100}=\Delta \delta^{010}<0$. Coherent strain energy is induced by the lattice distortion so as to maintain the coherency of the interface. When the interface has lots of mismatches, the energy of coherent strain will increase accordingly, in order to maintain a coherent interface relationship. A kind of relationship could be obtained as $E^{i j k} \propto \delta^{i j k}$, where $E^{i j k}$ is the coherent strain energy and $\delta^{i j k}$ is the coherent interface mismatch. What's more, the formula of $\Delta E^{i j k} \propto \Delta \delta^{i j k}$ is tenable ${ }^{[24]}$. When the $\Delta E^{100}$ and
$\Delta E^{010}$ decrease, to the contrary, the $\Delta E^{001}$ increases. To reduce the coherent strain energy of the two groups of $\gamma / \gamma^{\prime}$ interfaces, the $\gamma^{\prime}$ phase extends along [100] and [010] directions, respectively by means of atomic diffusion until the $\gamma^{\prime}$ phase connects together. The two-dimensional directional coarsening (P-type raft) occurs in $\gamma^{\prime}$ phase, which is perpendicular to the [001] stress axes. The $\gamma$ phase gradually disappears, and eventually a flaky rafting organization is formed. The above analysis shows that the coherent strain energy of the $\gamma / \gamma^{\prime}$ interface and the system's overall energy are the driving forces of $\gamma^{\prime}$ phase rafting.

\subsection{Directional migration behavior of $\mathrm{Al}, \mathrm{Re}, \mathrm{Co}$ and Mo}

We get the contents of alloying elements $\mathrm{Al}, \mathrm{Re}, \mathrm{Co}$ and $\mathrm{Mo}$ before and after creep by TEM, as shown in Fig.3. Al, Re, W, Mo and other elements are distributed unevenly within the $\gamma / \gamma^{\prime}$ structure of the DD6 alloy after full heat treatment in Fig.3a. The content of $\mathrm{Al}$ in $\gamma^{\prime}$ phase is more than that in $\gamma$ phase. $\mathrm{Al}$ mainly exists in the form of precipitation phase $\left(\mathrm{Ni}_{3} \mathrm{Al}\right)$ in the DD6 alloy, and only a little part of Al diffuses into the matrix, forming a solid solution. Re mainly diffuses into $\gamma$ phase, forming short-range ordered groups with the size of about 1 $\mathrm{nm}$. Compared with the independence of other solute atoms in solid solution, the affixion of Re substantially reduces the $\gamma^{\prime}$ coarsening kinetics and results in negative $\gamma / \gamma^{\prime}$ misfit alloys, which can reduce the diffusion rate of alloy element, prevent the movement of dislocation, and retard the diffusion of the coarsening of $\gamma^{\prime}$ precipitation phase ${ }^{[25]}$. Furthermore, about
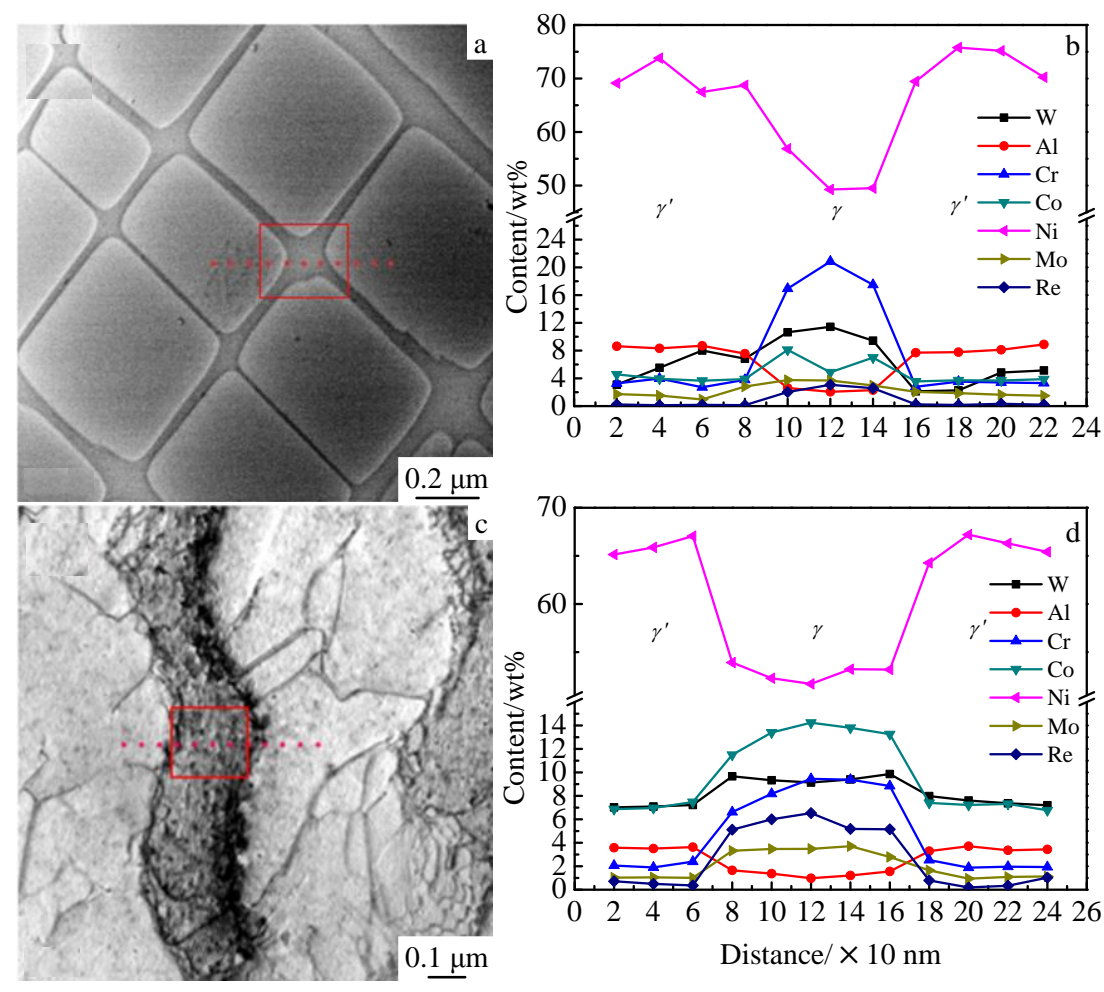

Fig.3 Contrast of microstructures and element contents before and after creep of alloy DD6: (a) microstructure of alloy DD6 before creep, (b) element content before creep, (c) microstructure of alloy DD6 after creep, and (d) elements content after creep 
$20 \%$ of Re diffuse into $\gamma^{\prime}$ phase, which directly affect the strength of $\gamma^{\prime}$ phase. It does not change the volume fraction of the $\gamma^{\prime}$ phase to any extent ${ }^{[26]}$. The contents of $\mathrm{W}$ have no differences in $\gamma$ and $\gamma^{\prime}$ phases; however, $\mathrm{W}$ concentrates obviously in the $\gamma / \gamma^{\prime}$ interface. The content of Mo in $\gamma$ phase is slightly more than that in $\gamma^{\prime}$ phase. The contents of $\mathrm{Al}, \mathrm{Re}, \mathrm{W}$ and Mo change greatly in $\gamma$ and $\gamma^{\prime}$ phase after creep rupture.

The main performances are as follows: the content of $\mathrm{Al}$ decreases significantly, while Re and Mo increase obviously in $\gamma$ phase. In order to better illustrate the components of the DD6 alloy before and after creep, we adopt the composition distribution ratios $\left(q_{i}^{\gamma^{\prime} / \gamma}=C_{i}^{\gamma^{\prime}} / C_{i}^{\gamma}\right)$ to express an element enrichment degree and describe element's directional diffusion behavior. The composition statistics are shown in Table 2 .

The content of $\mathrm{Al}$ in $\gamma^{\prime}$ phase decreases from $8.21 \%$ before rafting to $3.51 \%$ after rafting in Table 2 . Re and Co concentrate obviously in $\gamma$ phase after creep. The $\gamma^{\prime}$ phase rafts into a long strip, and the gable channel gradually disappears. The content of $\mathrm{Re}$ and $\mathrm{Co}$ in roof channel increases dramatically. In essence, the phenomenon is due to spreading of the elements of gable channel to roof channel. Meanwhile, the elements such as $\mathrm{Re}$ and Co have larger atomic radius, and easily form solid solution with the Ni. Therefore the diffusion is based on the process of cavitation. Diffusion activation energies of these elements are large, and the diffusion coefficients are small. Therefore, these elements can only spread in limited areas ${ }^{[27]}$. Rafting is formed in $\gamma^{\prime}$ phase within a very short time during the early stages of the creep. From above, we may come to a conclusion that elements in the gable channel can only spread to the crossing area of the gable channel and the roof channel, especially the Re and W, which have larger atomic radius, as shown in Fig.3. The microstructure of the crossing area was analyzed by energy dispersive spectrometry (EDS) in Fig.4.

Table 3 is the compositions of points A and B in Fig.4. On the edge of the $\gamma^{\prime}$ phase, the contents of Re and $\mathrm{W}$ are more than that in the roof channel. These data prove that the above analysis is reasonable. There is a lot of $\mathrm{Al}$ in both $\gamma$ and $\gamma^{\prime}$ phases. In the process of rafting, the $\mathrm{Ni}$ and $\mathrm{Al}$ in the gable channel participate in the formation of the precipitation phase $\gamma^{\prime}$. However, the $\mathrm{Al}$ in the gable channel is not enough to form abundant $\gamma^{\prime}$ phase. The Al diffuses from the gable channel to

Table 2 Composition statistics of the DD6 alloy before and after creep (wt\%)

\begin{tabular}{cccccc}
\hline & Alloy phase & $\mathrm{Al}$ & $\mathrm{Re}$ & $\mathrm{Co}$ & $\mathrm{Mo}$ \\
\hline \multirow{2}{*}{ Before } & $\gamma^{\prime}$ & 8.21 & 0.2 & 4.73 & 1.76 \\
creep & $\gamma$ & 2.32 & 2.56 & 10.5 & 3.47 \\
& $q_{i}^{\gamma^{\prime \prime \gamma}}$ & 3.54 & 0.078 & 0.45 & 0.5 \\
\hline \multirow{2}{*}{ After } & $\gamma^{\prime}$ & 3.51 & 0.56 & 7.35 & 1.1 \\
creep & $\gamma$ & 1.35 & 5.6 & 9.48 & 3.35 \\
& $q_{i}^{\gamma^{\prime \prime \gamma}}$ & 2.6 & 0.1 & 0.77 & 0.32 \\
\hline
\end{tabular}

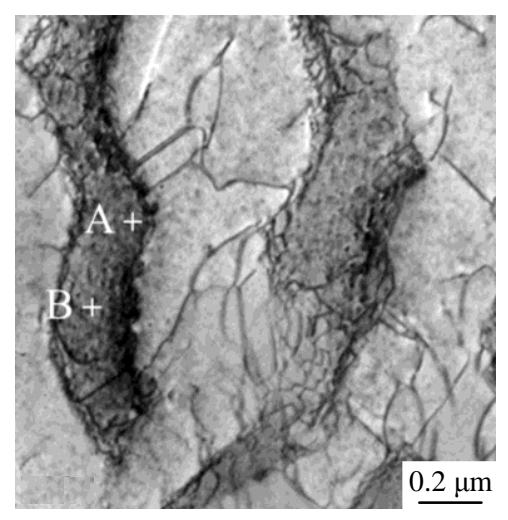

Fig.4 Crossing area of the matrix phase and the roof channel analyzed by EDS

Table 3 Composition statistics of the point $A$ and $B$ in Fig.4 after creep of alloy (wt\%)

\begin{tabular}{cccccccccc}
\hline Point & $\mathrm{Al}$ & $\mathrm{Cr}$ & $\mathrm{Co}$ & $\mathrm{Ni}$ & $\mathrm{Nb}$ & $\mathrm{Mo}$ & $\mathrm{Ta}$ & $\mathrm{W}$ & $\mathrm{Re}$ \\
\hline $\mathrm{A}$ & 0.81 & 9.37 & 13.76 & 52.33 & 0.54 & 3.33 & 3.17 & 10.16 & 6.56 \\
$\mathrm{~B}$ & 1.56 & 6.62 & 11.5 & 56.7 & 0.75 & 2.79 & 5.26 & 9.67 & 5.18 \\
\hline
\end{tabular}

the roof channel. Meanwhile, Re can effectively reduce the diffusion of $\mathrm{Al}$ and $\mathrm{Ni}$, which will suppress the exchange of elements between $\gamma$ and $\gamma^{\prime}$ phase ${ }^{[28]}$. This makes the spread of the elements only under the condition of higher temperature and stress, so as to improve the creep resistance and high temperature durable life of the alloy.

\section{Conclusions}

1) The gable channel completely disappears, and $\gamma^{\prime}$ phase expands along the direction which is perpendicular to the stress axes, and finally P-type microstructure is formed.

2) Re and Co concentrate obviously in $\gamma$ phase after creep. Elements in the gable channel can only be spread to the crossing area of the gable channel and the roof channel, especially Re and W.

3) The increase of coherent strain energy of the whole system becomes the driving force of $\gamma^{\prime}$ phase directional coarsening.

\section{References}

1 Wang C, Zhang J, Liu L et al. Journal of Alloys and Compounds[J], 2010, 508: 440

2 Mao H Z, Wen Z X, Yue Z F et al. Materials Science and Engineering $A[\mathrm{~J}], 2013,587: 79$

3 Reed R C. The Superalloys Fundamentals and Applications[M] London: Cambridge University Press, 2006

4 Hou N X, Wen Z X, Yue Z F. Materials Science and Engineering $A[\mathrm{~J}], 2009,510: 42$

5 Wu W P, Guo Y F, Wang Y S. Philosophical Magazine [J], 2011, 91: 357 
6 Xie H X, Yu T, Yin F X et al. Materials Science and Engineering $A[\mathrm{~J}], 2013,580: 99$

7 Yu J G, Zhang Q X, Yue Z F. RSC Advances[J], 2014, 4: 20789

8 Moverare J J, Johansson S, Reed R C. Acta Materialia[J], 2009, 57: 2266

9 Yu X X, Wang C Y, Zhang X N et al. Journal of Alloys and Compounds[J], 2014, 582: 99

10 Cheng K Y, Jo C Y, Jin T. Journal of Alloys and Compounds[J], 2011, 509: 7078

11 Latief F H, Kakehi K. Materials and Design[J], 2013, 49: 485

12 Tan X P, Liu J L, Jin T et al. Materials Science and Engineering $A[\mathrm{~J}], 2011,528: 8381$

13 Yang L, Li J R. Advances in Materials Research[J], 2013, 816: 90

14 Li J R, Zhong Z G, Tang D Z. Acta Metallurgica[J], 1999, 35: 266

15 Stiller K, Warren P J, Hansen V. Materials Science and Engineering A[J], 1999, 270: 27055

16 Yu X F, Tian S G, Du H Q et al. Materials Science and Engineering $A[\mathrm{~J}], 2009,506: 80$

17 Kaniyoor A, Ramaprabhu S. AIP Advances[J], 2012, 2: 32113
18 Yu T, Deng Q, Dong G. Applied Surface Science[J], 2011, 257: 5098

19 Markel D C, Zhang R, Shi T. Inflammation Research[J], 2009, 58: 413

20 Bian Z, Zhu J, Cao F et al. Chemical Communications[J], 2009, 25: 3789

21 Zhou N, Shen C, Mills M et al. Philosophical Magazine[J], 2010, 90: 405

22 Unocic R R, Zhou N, Kovarik L et al. Acta Materialia[J], 2011, 59: 7325

23 Tao Z, Wang C Y. Chinese Physics B[J], 2006, 15: 2087

24 Peng Z F, Ren Y Y, Fan B Z et al. Acta Metallurgica Sinca[J], 1999, 35(1): 1 (in Chinese)

25 Giamei A F, Anton D L. Metallurgical Transactions A[J], 1985, 16: 1997

26 Warren P J, Cerezo A. Materials Science and Engineering A[J], 1998, 250: 8

27 Zeng Q, Ma S W, Zheng Y R. Journal of Alloys and Compounds[J], 2009, 480: 987

28 Tian S, Su Y, Qian B. Materials and Design[J], 2012, 37: 236

\title{
DD6 单晶合金筏化过程中元素定向迁移行为
}

\author{
张世明 ${ }^{1}$, 余金桂 ${ }^{1}$, 黄泽银 ${ }^{1}$, 黄 荣 $^{1}$, 刘生发 ${ }^{1}$, 章桥新 ${ }^{1}$, 岳珠峰 ${ }^{2}$, 李雪伍 ${ }^{1}$ \\ (1. 武汉理工大学, 湖北 武汉 430070) \\ (2. 西北工业大学, 陕西 西安 710072)
}

摘 要: 对[001]取向 DD6 单晶合金进行 $1000{ }^{\circ} \mathrm{C} / 300 \mathrm{MPa}$ 条件下的拉伸蠕变试验, 以研究合金的筏化现象以及元素的定向迁移行为。 SEM 对合金显微组织的观察表明, $\gamma^{\prime}$ 相在温度和应力的作用下发生了筏化，且筏化方向与应力轴垂直，同时平行于应力轴的基体通道变 宽，垂直于应力轴的基体通道逐渐消失。 TEM 对合金的成分统计分析表明，合金中 $\mathrm{Al} 、 \mathrm{Re} 、 \mathrm{~W}$ 元素发生了定向迁移，其中 $\mathrm{Al}$ 向与应 力轴平行的基体通道扩散, 而 Re、W 向与应力轴垂直的基体通道扩散, 并主要富集于相互垂直的基体通道的交叉区域。

关键词: $\mathrm{Ni}$ 基合金; 蠕变; 定向迁移; 扩散

作者简介: 张世明, 男, 1992 年生, 硕士生, 武汉理工大学机电工程学院, 湖北 武汉 430070, 电话: 027-87218976, E-mail: 984818903@qq.com 